\title{
Effects of Swimming Training on Stress Levels of the Students Aged 11-13
}

\author{
Mihraç Köroğlu ${ }^{1}$, Korkmaz Yiğiter ${ }^{2, *}$ \\ ${ }^{1}$ Department of Physical Education and Sport, Private Sahin Colleges, Turkey \\ ${ }^{2}$ Department of Sport Management, Sport Sciences Faculty, Duzce University, Turkey
}

Copyright $\bigcirc 2016$ by authors, all rights reserved. Authors agree that this article remains permanently open access under the terms of the Creative Commons Attribution License 4.0 international License.

\begin{abstract}
The purpose of this research was to determine the effects of the swimming training program on stress levels of the students ages 11-13. To this end, 60 students from Private Şahin School in the Sakarya city participated in the study voluntarily. 60 students were divided into two groups and each group was included 30 students. Stress Level Scale II developed by Leighton (1989) was used in the study for pretests and posttests. After preliminary testing, the experimental group students participated in the swimming training in two sessions, each lasting two hours for 8 weeks. Posttests for two groups were administered at the end of the swimming training program. The data obtained from the present study conducted with an experimental design method were analyzed using SPSS statistical software. T test was used in the study to compare the results between pre-posttests of the experimental group and pre-posttests of the control group in different groups (Pretest of the experimental group x Pretest of the control group / Posttest of the experimental group $x$ Posttest of the control group). Also, paired Sample $\mathrm{T}$ test was used in the study to compare the results between pre-posttests of the experimental group and pre-posttests of the control group in the same groups (Pretest of the experimental group $\mathrm{x}$ Posttest of the experimental group / Pretest of the control group $\mathrm{x}$ Posttest of the control group). As a result of this study, there was a significant difference between pretest of the experimental group $(39.03 \pm 9.21)$ and posttest of the experimental group $(31.20 \pm 4.06)$. There was not a significant difference between pretest of the control group (36.43 \pm 8.13) and posttest of the control group $(40.56 \pm 9.21)$. Research results showed that swimming training program was effective to reduce stress level of the students ages 11-13.
\end{abstract}

Keywords Swimming Training, Stress Level, Student and Sports

\section{Introduction}

Swimming is the only sport to be recommended in more than $80 \%$ of the medical cases and to have a large target audience, accessible to both children and the elderly. From a psychological perspective, swimming reduces the mental tensions and anxiety, caused by everyday stress and the competition one, while avoiding hostility and frustration in life, in a beneficial way [1]. Swimming is also a fun way to release stress after a work day. The contact with the water is very beneficial and helps to loosen up the body and the mind. The regular rhythm of the stroke, the immersion in the water and the concentration on the technique quickly feel like a relaxing meditation in the water. Swimming can improve your overall health. It's an ideal workout for your heart and circulation, as you are using your whole body to swim [2]; therefore, your heart has to pump blood harder than it normally would to your arms and legs. Additionally, length swimming is great for your lungs as it forces you to breathe in a deeper, more rhythmic fashion. Swimming is also a very social sport. When you start to go to the pool, you quickly get to know the like-minded regulars. To chat about various topics and to exchange swimming tips and tricks while you relax in the water is very enjoyable. The swimming pool is also a place where you can chat with people of all ages, which becomes rare in our society [2]. For most people, health and mental wellbeing improve, and the problematic behaviors are reduced, though the incidence of mental disorders, such as depression, increases $[1,3]$. Both with emerging adulthood and young adulthood, physical and sensory capabilities are excellent, the factors related to lifestyle, such as nutrition, obesity, exercise, sleep, smoking and drinking or substance abuse, can influence health and survival. Middle-aged adults have a greater likelihood, than the younger adults or the older adults, to suffer from serious mental disorders: sadness, anxiety, agitation, feelings of hopelessness and worthlessness [1, 3].

Children aged 10 to 12 years are in a transitional stage from childhood to adolescence; this period is a turning point in the lives of children and involves psychologically stressful challenges that may result in depressive symptoms 
$[4,5]$. For example, the stress a child brings to school can impact the climate of the school by influencing student behaviors and academic achievement. Common stressors in late adolescence, when students are beginning college, include transitioning from home to school and transitioning from dependence on family to oneself and one's friends $[6,5]$. So regular physical activity has benefits for both physiological and psychological health $[7,8]$. Similarly, a growing number of experimental studies and the existence of several plausible theoretical explanations support the idea that regular exercise yields mental health benefits as well [8].

In the light of the comments above, this study aimed to determine the effects of the swimming training program on the stress levels of the students ages 11-13. To this end, it was thought that the participants in the present study will decrease their stress levels by participating in a swimming training program designed by the experts related to sport branch.

\section{Materials and Methods}

\subsection{Participants}

60 participants were selected randomly from 235 students attending private şahin school in the Sakarya city in the Marmara region of the Turkey. 60 students were divided into two groups as experimental and control. All testees were voluntarily and interestedly included in the present research. The attendance of participants was noted by the instructor for each swimming training. All swimming training program were recorded by the researcher as video.

\subsection{Instrument}

Stress Level Scale I-II; In the present research, the Stress Level Scale I-II developed by Leighton (1989) was used to collect information on participants [5]. Stress Level Scale I-II was adapted to Turkish by Baltas (1994) [9]. In this study, stress scale II was performed on children attending 6th and 7th grade. Stress scale II includes 25 items. Scores between 27 and 29 are within normal range; scores between 30 and 35 are at the high boundary, and scores above 36 suggest high stress.

\subsection{Procedure}

Initially, all participants received information about the schedule in relation to the swimming training, voluntary participation and confidentiality were assured. In this study designed as an quasi experimental research, the Stress Level Scale was distributed among the students before the swimming training program. In the same way, the same scale was performed on the same students at the end of the swimming training program. Participants were randomly assigned to experiment and control groups by using a random number generated using Excel computer software. The control group said that they did not participate in any organized and structured swimming training program and so they continued their normal daily life. Participants in the experiment group participated in a swimming training program planned as two sessions, each lasting two hours for 8 weeks. Informed consent was signed by participants before the swimming competition, and also all scale used in this study were anonymous. Consent from Private Sahin School management and family of the students was obtained for the research.

\subsection{Data Analysis}

The data was analyzed by SPSS 16.0 Package Program. Descriptive statistics, independent sample $t$ test and paired samples $t$ test analysis were used to analyze the data. Level of significance was determined to be 0.05

\section{Results}

Table 1. Differences regarding scores of the stress level between pre test of two groups

\begin{tabular}{cccccc}
\hline Pre Test & $N$ & $X$ & $S D$ & $t$ & $p$ \\
\hline Experiment & 30 & 39,03 & 9,21 & & \\
\hline Control & 30 & 36,43 & 8,13 & & \multirow{2}{*}{252} \\
\hline
\end{tabular}

As can be seen table 1, there was not a significant difference between experiment group's X stress Pre-Test score 39,03 $\pm 9,21$ and control group's $X$ stress Pre-Test score $36,43 \pm 8,13(\mathrm{p}>0.05)$.

Table 2. Differences regarding scores of the stress level between post test of two groups

\begin{tabular}{cccccc}
\hline Post Test & $N$ & $X$ & $S D$ & $t$ & $p$ \\
\hline Experiment & 30 & 31,20 & 4,06 & & \\
\cline { 1 - 3 } Control & 30 & 40,56 & 8,73 & &, 000 \\
\hline
\end{tabular}

As can be seen table 2, there was a significant difference between experiment group's $\mathrm{X}$ stress Post-Test score $31,20 \pm 4,06$ and control group's X stress Post-Test score $40,56 \pm 8,73(\mathrm{p}>0.05)$.

Table 3. Differences regarding scores of the stress level between pre and post test of two groups

\begin{tabular}{ccccccc}
\hline Groups & Test & $N$ & $X$ & $S D$ & $t$ & $p$ \\
\hline \multirow{2}{*}{ Experiment } & Pre test & 30 & 39,03 & 8,73 & & \\
\cline { 2 - 5 } & Post test & 30 & 31,20 & 4,06 & & \multirow{2}{*}{000} \\
\hline \multirow{2}{*}{ Control } & Pre test & 30 & 36,43 & 8,13 & & \multirow{2}{*}{$-1,1305$} \\
\cline { 2 - 5 } & Post test & 30 & 40,56 & 9,21 & & \\
\hline
\end{tabular}

As can be seen table 3, there was a significant difference between experiment group's $\mathrm{X}$ stress Pre-Test score $39,03 \pm 8,73$ and control group's $X$ stress Post-Test score $31,20 \pm 4,06(\mathrm{p}>0.05)$. There was not a significant difference 
between control group's X stress Pre-Test score 36, 43 \pm 8 , 13 and control group's X stress Post-Test score 40, 56 $\pm 9,21$ $(\mathrm{p}>0.05)$.

\section{Discussion}

This study aimed to determine the effects of the swimming training program on the stress levels of the students ages 11-13. To this end, 60 students from a school participated in the study voluntarily. Results of the research showed that there was a significant difference between experiment group's X stress Pre-Test score 39,03 $\pm 8,73$ and

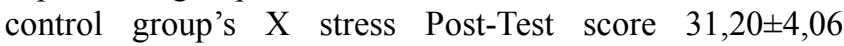
$(p>0.05)$. There was not a significant difference between control group's X stress Pre-Test score 36,43 $\pm 8,13$ and control group's X stress Post-Test score 40,56 $\pm 9,21$ $(\mathrm{p}>0.05)$.

Donaldson ve Ronan (2006) examined the relationship between children's sports participation and emotional well-being including self-reported emotional and behavioral problems and multidimensional aspects of self-concept. Their study found that increased levels of sports participation had a positive relationship with aspects of emotional and behavioral well-being, particularly self-concepts. Their results also showed that children with increased perceptions of sport-related competencies reported significantly fewer emotional and behavioral problems than did children who were, by external standards (e.g., teacher rating, number of sporting achievements), actually competent at sport. The study also found particular areas of sports participation to be positively associated with self-concept. Evidence suggested a similar beneficial association with some aspects of behavior problems [10]. Steptoe ve Butler (1996) assessed the association between extent of participation in regular sport or vigorous recreational activity and emotional wellbeing in adolescents aged 16 years. 2223 male and 2838 female students participated in their study. They found that emotional wellbeing is positively associated with extent of participation in sport and vigorous recreational activity among adolescents. Although causal associations cannot be assumed in this cross-sectional analysis, their results are consistent with experimental evidence that vigorous exercise has favorable effects on emotional state [11].

Muhamad et al., (2013) determined the changes in the anxiety levels of female students in relation to their swimming skills the results of their study showed that learning how to swim decreases the anxiety levels of female students. they suggested that taking up swimming activity might have benefits for students with high levels of anxiety [12]. Petrescu et al., (2014) investigated the effects of practicing swimming on the psychological tone in adulthood. Their study results showed that regular swimming practice has significant effects in terms of psychological tone. This result allows them to say that the practice of swimming has significant influence on the mental tone [1]. Kalkan et al., (2010) investigated the effects of swimming training for 10 weeks on children's loneliness levels. In her study, 146 children was formed and a control group consisting of 73 children and an experimental group consisting of 73 children were formed taking the scores of the scale into consideration. The mean age of the children on the experimental group was 9.87 years, and the mean age of the children on the control group was 9.66 years. The results of their study suggest that benefits of swimming exercise decrease children's loneliness levels. This result supported our study from psychological improving perspective [13].

Santhiago et al. (2011) investigated the influence of a 14-week swimming training program on psychological, hormonal, and performance parameters of elite women swimmers. Ten Olympic and international-level elite women swimmers were evaluated 4 times along the experiment (i.e., in $\mathrm{T} 1, \mathrm{~T} 2, \mathrm{~T} 3$, and $\mathrm{T} 4$ ). On the first day at 8:00 am, before the blood collecting at rest for the determination of hormonal parameters, the athletes had their psychological parameters assessed by the profile of mood-state questionnaire. At 3:00 am, the swimmers had their anaerobic threshold assessed. On the second day at 3:00 am, the athletes had their alactic anaerobic performance measured. Vigor score and testosterone levels were lower $(p \leq 0.05)$ in $\mathrm{T} 4$ compared with $\mathrm{T} 3$. In addition, the rate between the peak blood lactate concentration and the median velocity obtained in the alactic anaerobic performance test increased in T4 compared with T3 $(p \leq 0.05)$. Psychologically, the negative scores (i.e., tension, depression, anger, fatigue, confusion, and total mood disturbance) are enhanced at the end of the training period. This result is supported our study from psychological improving perspective. This result supported our study results regarding stress levels [14]. Sahin et al., studied about the physical activity and sport as a preventive factor in building resilience. They stated that physical activities influenced psychological conditions of people positively [15]. Thorlindsson et al., (1990) studied about the sport participation and perceived health status: a study of adolescents. They stated that sport participation has a substantial direct effect on perceived health, controlling for other health related behaviors, psychological distress and disease status. Sport participation also affects perceived health indirectly through distress and smoking, but does not seem to operate through alcohol consumption [16]. Calfaz and Taylor, (1994) studied about effects of physical activity on psychological variables in adolescents. Their results showed that physical activity was consistently related to improvements in self-esteem, self-concept, depressive symptoms, and anxiety/stress. The effect sizes were $+.12 .--.15$. and --.38 for self-esteem/self-concept, stress/anxiety, and depression, respectively [17]. Tayor et al, (1985) studied that vigorous physical activity has positive effects on mental health in both clinical and nonclinical populations. Their paper reviewed the evidence for this claim and provides recommendations for future studies. The 
strongest evidence in their study suggested that physical activity and exercise probably alleviate some symptoms associated with mild to moderate depression. The evidence also in their study suggested that physical activity and exercise might provide a beneficial adjunct for alcoholism and substance abuse programs; improve self-image, social skills, and cognitive functioning; reduce the symptoms of anxiety; and alter aspects of coronary-prone (Type A) behavior and physiological response to stressors [18]. It is seen that many studies results were consistent with the present study. For future studies, it can be suggested that some programs regarding swimming for all different age categories should be improved for seeing the difference between ages and programs.

\section{Conclusions}

So many studies showed that physical activities are very important for human health. Therefore, it can be said that the present study results supported many studies done about he physical activities and psychological health in the past and current literature. Results of the study showed that swimming training program was effective to reduce stress level of the students ages 11-13. So people can be encouraged to participating in swimming sports or any program including physical activity.

\section{REFERENCES}

[1] Petrescu, S, Pitigoi, G, Păunescu, M, (2014). The Effects of Practicing Swimming on The Psychological Tone in Adulthood, Procedia - Social and Behavioral Sciences, 159, 74-77.

[2] Online available from www.enjoy-swimming.com

[3] Papalia DP., Olds SW., \& Feldman RD., (2010). Dezvoltarea umană. București, Editura Trei, p.423.

[4] Herman-Stahl, M., \& Peterson, A. C. (1996). The protective role of coping and social resources for depressive symptoms among young adolescents. Journal of Youth and Adolescence, $25,733-753$.

[5] Yiğiter, K. \& Kuru, M. (2014). Investigating the Swimmers' Stress Levels Before and after the Swimming Competition.
Procedia - Social and Behavioral Sciences, 152, 480-482.

[6] Cohn, A. M. (2008). Helping children and staff understand and minimize stress. NASP Communiqué, 36(5).

[7] Aşçı, F.H. (2003). The effects of physical fitness training on trait anxiety and physical self-concept of female university students. Psychology of Sport and Exercise, 4(3), 255-264. http://dx.doi.org/10.1016/S1469-0292(02)00009-2.

[8] Binsinger, C., Laure, P., \& Ambard, M.F. (2006). Regular extracurricular sports practice does not prevent moderate or severe variations in self-esteem or trait anxiety in early adolescents. Journal of Sports Science and Medicine, 5, 123-129.

[9] Baltaş A. ve Baltaş Z. (1999). Stres ve Başaçıkma Yolları. Ondokuzuncu Basım. Remzi Kitabevi, İstanbul.

[10] Donaldson SJ, Ronan KR. (2006). The effects of sports participation on young adolescents' emotional well-being. Adolescence, 41(162), 369-89.

[11] Steptoe A.S. Butler N. (1996). Sports Participation and Emotional Wellbeing in Adolescents. The Lancet, 347(9018), 1789-1792.

[12] Muhamad, TAB, Sattar, H. Abadi, FH, Haron, Z. (2013). The Effect of Swimming Abilityon the Anxiety Levels of Female College Students. Asian Social Science, 9,15.

[13] Kalkan, M, Tekat, A, Koç, HE, Sözen H, (2010). The effects of swimming training on children's loneliness levels: An experimental study. Journal of Physical Education and Sport Sciences, 5,1 .

[14] Santhiago V, Da Silva AS, Papoti M, Gobatto CA. (2011). Effects of 14-week swimming training program on the psychological, hormonal, and physiological parameters of elite women athletes. Journal Strength Condition Research, 25(3), 825-32. doi:10.1519/JSC.0b013e3181c69996.

[15] Şahin M. Yetim A. Çelik A. (2012). physical activity and sport as a preventive factor in building resilience. The Journal of Academic Social Science Studies, 5(8), 373-380.

[16] Thorlindsson, T., Viltigonsson, R., Valgerirsson, G. (1990). Sport participation and perceived health-status. A study of adolescents. Social Science and Medicine 31, 551-556.

[17] Calfaz, K.J. \& Taylor, W.C. (1994) studied about effects of physical activity on psychological variables in adolescents. Pediatric Exercise Science, 6, 406-423.

[18] Tayor, C.B., Sallis, JF. \& Nedler, R. (1985). The relation of physical activity and exercise to mental health. Public Health Reports, 100(2), 195-202. 